Carla Guimarães GIANINI ${ }^{1}$ Carlos Alberto HUSSNI ${ }^{1}$ Ana Liz Garcia ALVES ${ }^{1}$ José Luiz de Mello NICOLETTI ${ }^{1}$ Armen THOMASSIAN ${ }^{1}$ Júlio Lopes SEQUEIRA ${ }^{1}$ Suzane Lilian BEIER ${ }^{1}$ Rebeca Alves WEIGEL ${ }^{1}$

Correspondências para: CARLOS ALBERTO HUSSNI Departamento de Cirrugia e Anestesiologia Veterinária

Faculdade de Medicina Veterinária e Zootecnia

Universidade Estadual Paulista Distrito de Rubião Júnior, $\mathrm{s} / \mathrm{n}^{\circ}$ 18618000 - Botucatu -SP

Recebido para publicação: 09/03/2005 Aprovado para publicação: 13/02/2006

\title{
Restabelecimento funcional do tendão extensor digital longo submetido a ressecção parcial em equinos: observação macroscópica, histopatológica e ultra-sonográfica
}

\author{
1 - Faculdade de Medicina Veterinária e Zootecnia da Universidade Estadual \\ Paulista, Botucatu - SP
}

\begin{abstract}
Resumo
Objetivou-se estudar os aspectos macroscópicos, ultra-sonográficos e histopatológicos do tecido neoformado no local da ressecção parcial do tendão extensor digital longo em 10 eqüinos, no momento do restabelecimento funcional do membro com o animal em locomoção à passo. $\mathrm{O}$ exame macroscópico foi realizado a cada 48 horas, o planimétrico das feridas a cada 10 dias, o ultra-sonográfico a cada 15 dias e o histopatológico no final do experimento. As feridas mostraram tecido de granulação em retração e exuberante, sem epitelização total, com aspectos ultra-sonográficos desorganizados diferentes do tendão íntegro e os exames histopatológicos revelaram tecido cicatricial em formação. O restabelecimento funcional médio foi de 45,9 dias, com o tecido neoformado na região da tenectomia permitindo o restabelecimento funcional do membro operado.
\end{abstract}

Palavras-chave: Eqüinos. Tendão extensor

\section{Introdução}

Os tendões flexores digitais são importantes estruturas de suporte do peso do animal, enquanto que os tendões extensores digitais têm a função de suporte do peso do membro nas fases de elevação e avanço na locomoção ${ }^{1,2}$.

Lacerações de tendão extensor digital, com grande ocorrência em eqüinos, estão associadas com feridas de avulsão, podendo ocorrer exposição óssea na face dorsal do metacarpo ou do metatarso $0^{1,3,4,5}$. Eqüinos portadores destas lesões arrastam o casco à locomoção, flexionando as articulações distais de modo involuntário, demonstrando incapacidade para estender o membro, restabelecendo a função extensora quando tratados com imobilização, podendo entretanto resultar em deformidade flexora ${ }^{1,4,6,7}$.

Com o objetivo de se estudar o restabelecimento funcional na ruptura do tendão extensor digital longo de eqüinos, avaliou-se o tempo total de restabelecimento e os aspectos macroscópicos, ultrasonográficos e histopatológicos da cicatrização deste tendão.

\section{Materiais e Métodos}

Foram utilizados dez eqüinos adultos, hígidos, com normalidade do aparelho locomotor confirmado clinicamente e por exame ultra-sonográfico (Aloka SSD 900 $7,5 \mathrm{mHz}$ - Japan). No terço distal, sobre a face dorsal do metatarso direito de cada animal, procedeu-se a ressecção de fragmento abrangendo da pele ao tendão extensor digital longo, seguindo molde rígido retangular $(6 \times 4 \mathrm{~cm})$, estando o animal sob anestesia geral e o local preparado conforme procedimento pré-operatório de rotina. Imediatamente após a tenectomia parcial aplicou-se penso protetor com tala rígida de PVC, mantendo-se o membro em extensão. Após a cirurgia cada animal recebeu penicilina benzatina (Pentabiótico Veterinárioâ) (20.000 UI/kg) IM e vedaprofeno (Quadrisol 100â) (2 mg/kg) 
oral a cada 12 horas, durante 10 dias. A cada 48 horas foi realizado curativo local, utilizando-se glicerina iodada $5 \%$ na ferida, aplicando-se penso com tala mantendo a porção distal do membro em extensão.

Após a cirurgia, procedeu-se exame clínico diário durante a primeira semana e posteriormente a cada 7 dias até o restabelecimento funcional do membro operado. As lesões foram avaliadas macroscopicamente a cada 48 horas até o término do experimento. Traçando-se o contorno das feridas em plástico transparente, realizou-se a planimetria (Planimeter K23 - Japan) imediatamente após a cirurgia e repetiu-se a cada dez dias até o restabelecimento funcional do tendão operado.

O restabelecimento funcional do membro submetido a tenectomia parcial foi considerado com a capacidade do animal realizar as fases de elevação e avanço do membro operado, em locomoção a passo, observado diariamente a partir do $30^{\circ}$ dia pós-operatório.

Os exames ultra-sonográficos foram realizados a cada 15 dias após o procedimento operatório e no momento do restabelecimento funcional do membro operado. No dia do restabelecimento funcional foram realizadas biópsias da ferida envolvendo as partes proximal, central e distal desta e os fragmentos submetidos a exames histopatológicos, com as lâminas coradas com Hematoxilina-eosina e Tricrômio de Masson.

\section{Resultados}

Os animais operados mantiveram normalidade paramétrica clínica durante todo o experimento.

O tempo total médio de restabelecimento do membro operado nos dez animais foi de 45,9 dias (desvio padrão $=3,41$ ), tendo variado de 41 a 53 dias (Tabela 1). As avaliações macroscópicas das feridas revelaram sangramento local imediato, formação de tecido de granulação a partir do quarto dia, com sangramento discreto até o $30^{\circ}$ dia. Observou-se ainda, edema perilesional até o $8^{\circ}$ dia, com discreta exsudação sero-fibrinosa e tecido de granulação presentes até o final. Três animais mostraram tecido de granulação exuberante e os sete demais mostraram epitelização junto aos bordos da ferida. Estes aspectos foram

Tabela 1 - Tempo total (T) (dias), de cada animal para o restabelecimento funcional do membro submetido à ressecção parcial do tendão extensor digital longo, com a média e desvio padrão (DP)

\begin{tabular}{|c|c|c|c|c|c|c|c|c|c|c|c|c|}
\hline & 1 & 2 & 3 & 4 & 5 & 6 & 7 & 8 & 9 & 10 & média & DP \\
\hline $\mathrm{T}$ & 45 & 45 & 45 & 45 & 50 & 41 & 53 & 43 & 47 & 45 & 45,9 & 3,41 \\
\hline
\end{tabular}

Tabela 2 - Superfície $\left(\mathrm{cm}^{2}\right)$ das feridas nos diferentes momentos (dias) nos 10 animais, com média e desvio padrão para os momentos (DP - desvio padrão/RF - dia do restabelecimento funcional), Botucatu-SP, 2004

\begin{tabular}{ccccccccccccc}
\hline & 1 & 2 & 3 & 4 & 5 & 6 & 7 & 8 & 9 & 10 & MÉDIA & DP \\
0 & 22,0 & 22,0 & 25,0 & 22,0 & 20,0 & 17,0 & 21,0 & 20,0 & 20,5 & 23,0 & 21,25 & 2,12 \\
10 & 30,0 & 47,0 & 35,0 & 32,0 & 31,0 & 24,0 & 33,0 & 33,0 & 21,0 & 38,0 & 32,4 & 7,15 \\
20 & 42,0 & 39,0 & 37,0 & 29,0 & 24,0 & 31,0 & 30,0 & 30,5 & 28,5 & 40,0 & 33,1 & 5,95 \\
30 & 51,0 & 29,0 & 24,0 & 25,0 & 13,0 & 19,5 & 14,0 & 21,0 & 31,0 & 44,0 & 27,15 & 12,27 \\
40 & 31,0 & 29,0 & 21,0 & 14,0 & 6,0 & 10,0 & 8,0 & 14,0 & 33,5 & 32,0 & 19,85 & 10,75 \\
50 & - & - & - & - & - & - & 4,5 & - & - & - & $*$ & $*$ \\
RF & 34,0 & 27,0 & 17,0 & 9,0 & 4,0 & 10,0 & 4,0 & 12,0 & 23,5 & 31,0 & 17,15 & 11,07 \\
\hline
\end{tabular}

* valor único do animal 7, desconsiderados a média e o desvio padrão 
observáveis a partir do $20^{\circ}$ dia. Considerado o período total de observação, nenhum animal mostrou epitelização completa da ferida.

A planimetria das feridas (Tabela 2) variou com aumento da área em quatro dos animais e redução da área em seis destes. Para os dez animais a média inicial foi 21,25 $\mathrm{cm}^{2}$ (desvio padrão $=2,12$ ) e a média final foi $17,15 \mathrm{~cm}^{2}$ (desvio padrão=11,7) no restabelecimento funcional do membro. Os três animais com presença de tecido de granulação exuberante apresentaram aumento da superfície das feridas entre os momentos inicial e final (Figura 1).

Os exames ultra-sonográficos aos 15 dias mostraram escore de ecogenicidade de grau 01 Gnovese et al.8, com predominância ecóica, com pontos anecóicos. Aos 30 dias mantiveram-se com grau 01, com discreta presença de pontos anecóicos. Aos 45 dias (Figura 3), semelhante ao momento final com o restabelecimento funcional do membro, observou-se maior homogeneidade do tecido neoformado, porém ainda desorganizado. Em todos os momentos observou-se atividade circulatória no tecido neoformado.

Nos exames histopatológicos, em ambas colorações, observou-se vascularização acentuada com grande número de capilares, arteríolas e vênulas de diferentes calibres nas transições distal e proximal entre o tendão e o tecido neoformado. O tecido intersticial perivascular mostrou edema discreto. A biópsia da região distal, média e proximal do tecido neoformado mostrou superfície ulcerada com epitélio acantótico nos bordos. Abaixo deste ocorreu tecido de granulação com grande número de fibroblastos e presença discreta de fibras colágenas com arranjo paralelo, vascularizado e com edema intersticial. $O$ infiltrado difuso presente compôs-se predominantemente por neutrófilos, observados ainda raros mononucleares e eosinófilos. Nas regiões mais profundas o tecido de granulação mostrou presença marcante de fibras colágenas e redução acentuada da vascularização, com infiltrado mononuclear, perivascular e de grau moderado.

\section{Discussão}

As feridas oriundas das lesões induzidas na ressecção parcial aplicada mostraram evolução semelhante à cicatrização por segunda intenção descrita para a pele $e^{9,10}$, com fase inicial expansiva, aumentando a área, seguindo a retração a partir do $30^{\circ}$ dia, seguindo em retração até o final das observações. Os três animais portadores de tecido de granulação exuberante, reiteram as descrições das complicações da ruptura tendinosa ${ }^{3,11,12,13}$ com relação direta entre o aumento do tecido de granulação e a área da ferida.

O tempo para o restabelecimento funcional do membro mostrou-se variável, acima de 40 dias conforme descrito ${ }^{1,9}$ e não sugeriu relação com o tecido de granulação exuberante ou com o tamanho da superfície da ferida observado pela planimetria.

Nos exames ultra-sonográficos, a graduação da ecogenicidade do tecido neoformado no local da tenectomia ${ }^{2}$ foi útil como parâmetro, sem, entretanto substituir a descrição dos exames macroscópicos e histopatológicos, não se mostrando absolutamente ideal como único método para as avaliações pós-operatórias, tratando-se de metodologia direcionada principal-mente a lesões tendíneas, mas revelando o tecido neoformado como desorganizado e bastante distinto do tendão normal observado no pré-operatório.

Considerando-se a similaridade histopatológica dos dez animais, não foi possível relacionar-se os achados histopatológicos com o tempo total de restabelecimento do membro operado, destacando-se a fase imatura e desorganizada da cicatrização do tendão, estruturalmente diferente do tendo íntegro, demonstrando entretanto que este tecido conjuntivo fibroso neoformado substituiu o tendão no restabelecimento da função extensora digital. 


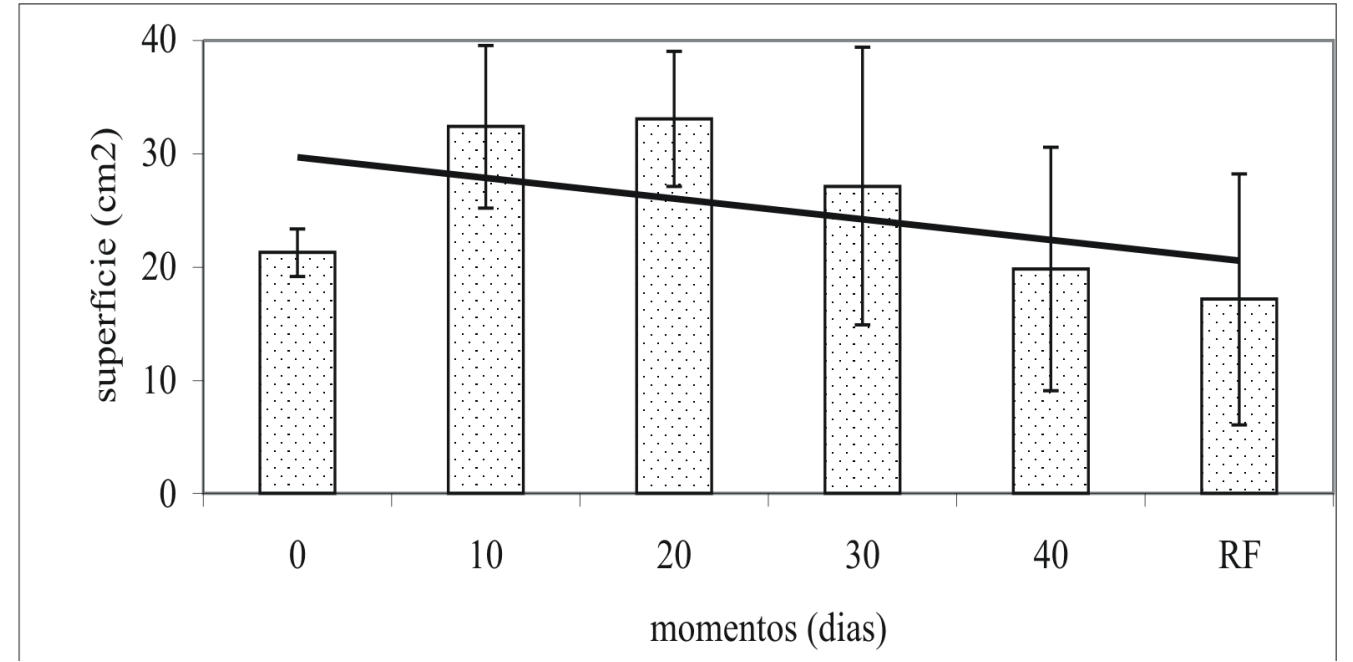

Figura 1 - Superfícies médias das lesões $\left(\mathrm{cm}^{2}\right)$ nos diferentes momentos, adicionado o desvio padrão para cada momento e linha de tendência (RFdia do restabelecimento funcional)

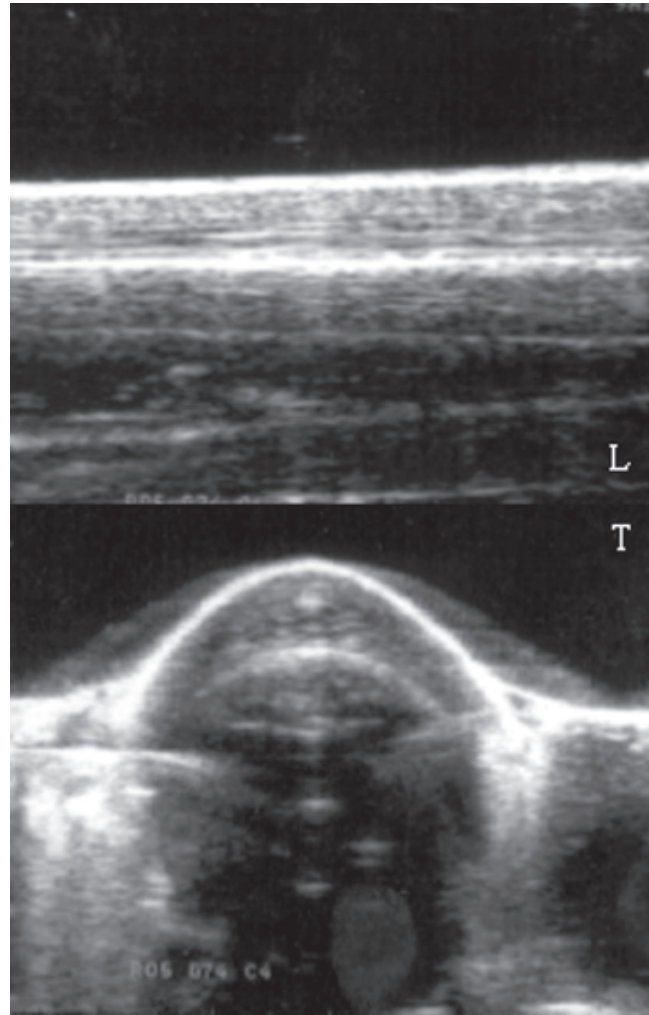

Figura 2 - Imagens ultra-sonográficas do tendão extensor digital longo íntegro no momento pré-operatório ( $\mathrm{L}$ - longitudinal / T transversal)

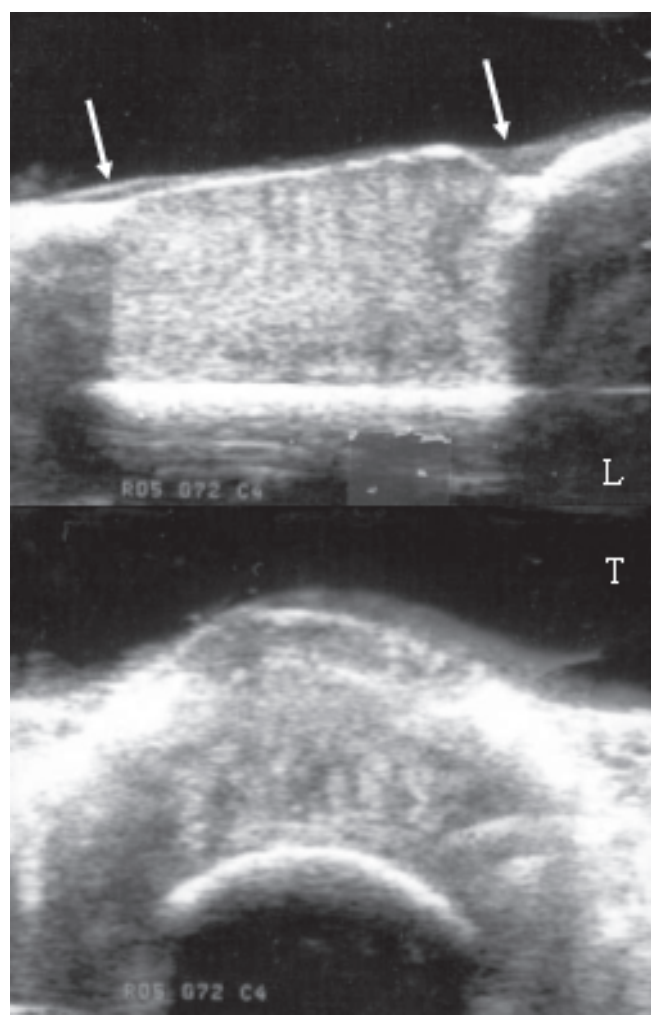

Figura 3 - Imagens ultra-sonográficas do tecido neoformado, 45 dias após a cirurgia, no momento final com o restabelecimento funcional do membro $(\mathrm{L}-$ longitudinal / $\mathrm{T}$ - transversal/setas transição entre o tendão e o tecido neoformado) 


\section{Conclusão}

Concluiu-se que o tecido conjuntivo fibroso neoformado, em organização no local da ressecção do tendão extensor digital longo restabeleceu a função tendínea extensora, sendo o exame ultra-sonográfico eficiente no detalhamento estrutural, pelas características não invasivas, isto confirmado pela histopatologia, com maior precisão diagnóstica.

\title{
Functional restoration of the long digital extensor tendon in horses after parcial tenectomy: gross, histopathologycal and ultrasonographic evaluation
}

\begin{abstract}
The objective of this work was to study the macroscopic, ultrasonographic and histopathologic aspects from the newly formed cicatricial tissue at the site of the partial resection of the long digital extensor tendon in 10 equines at the moment of functional restoration of the limb with the animal in walk locomotion. The macroscopic exam was performed every 48 hours, the planimetric mensuration every 10 days, the ultrasonographic exam every 15 days and the histopathologyc exam at the end of the study. The wounds showed granulation tissue in retraction, without total lesion epithelization, and the aspects ultrasonographics revealed wound healing with newly formed tissues with variable density and high neovascularization without tendon structural reorganization. The histopathology showed newly formed vascularized tissue, with leukocytic infiltrate and collagenous deposition without full epithelization. The cicatrization tissue formed in the resection region of the tendon, immature and without the structural organization of the normal tendon, showed to be able to functional restoration of the operated limb.
\end{abstract}

\section{Referências}

1 STASHAK, T. S. Adams lameness in horses. 4. ed. Philadelphia: Lea \& Febiger, 1987. 764 p.

2 WISSDORF, H. GERHARDS, H; HUSKAMP, B. Praxisorientierte Anatomie des Pferdes. Hannover: $M$ \& H Schaper Alfeld, 1998. 628 p.

3 BAXTER, G. M. Retrospective study of lower limb wounds involving tendons, tendon sheats or joints. In: ANNUAL CONVENTION OF THE AMERICAN ASSOCIATION OF EQUINE PRACTITIONERS, 33., New Orleans, 1986. Proceedings... New Orleans: American Association of Equine Practitioners, 1987. p. 715-28.

4 STASHAK, T. S. Management of wounds associated with tendons, paratendons, and tendon sheats. In: STASHAK, T. S. Equine wound management. Philadelphia: Lea \& Febiger, 1991. p. 238-257.

5 WATKINS, J. P. Treatment principles of tendon disorders. In: AUER, J.A. Equine surgery. Philadelphia: WB Saunders, 1992. p. 916-924.
6 THOMASSIAN, A. Enfermidades dos cavalos. 2. ed. São Paulo: Varela. 1996. 643 p.

7 WYN-JONES, G. Tendon injuries. In: WYN-JONES, G. Equine lameness. Oxford: Blackwell Scientific, 1988. p. 224-236.

8 GENOVESE, R. L. et al. Diagnosis ultrasonography of equine limbs. Veterinary Clinics of North America: Equine Practice, v. 2, p.127-144, 1986.

9 HUSSNI, C. A. et al. Comparação entre timerosal, glicerina iodada e iodo polivinipirrolidona com açúcar, na cicatrização de pele em equinos. Arquivos de Ciências veterinárias e Zoologia da Unipar, v.4, n.2, p.109-117, 2001.

10 WLUDARSKI, A. R. L., HUSSNI, C. A. Avaliação de diferentes produtos tópicos na cicatrização de pele em eqüinos. In: X CONGRESSO DE INICIAÇÃO CIENTÍFICA DA UNESP, 10., Araraquara, 1998. Anais. Araraquara: UNESP, 1998. p. 372.

11 BELKNAP, J. K. et al. Extensor tendon lacerations in horses: 50 cases (1982-1988). Journal of the American Veterinary Medicine Association, Michigan, v. 203, n. 
3, p. 428-431, 1993.

12 FOLAND, J. W. et al. Traumatic injuries involving tendons of the distal limbs in horses: a retrospective study of 55 cases. Equine Veterinary Journal, Fort Collins v. 23, p. 422-425,1991.

13 JANSSON, N. Digital extensor tendon lacerations in horses: a retrospective evaluation of 22 cases. Journal of Equine Veterinary Science, Ithaca, v.15, n.12, p. 537-540, 1995. 